\title{
Polytene Chromosome Map and Inversion Polymorphism in Drosophila mediopunctata
}

\author{
Galina Ananina, Alexandre A Peixoto*, Wilma N Souza, Louis B Klaczko ${ }^{+}$ \\ Departamento de Genética e Evolução, Instituto de Biologia, Universidade Estadual de Campinas, Unicamp, Caixa Postal 6109, \\ 13083-9790 Campinas, SP, Brasil *Departamento de Bioquímica e Biologia Molecular, Instituto Oswaldo Cruz-Fiocruz, \\ Rio de Janeiro, RJ, Brasil
}

Drosophila mediopunctata belongs to the tripunctata group, and is one of the commonest Drosophila species collected in some places in Brazil, especially in the winter. A standard map of the polytene chromosomes is presented. The breakpoints of the naturally occurring chromosomal rearrangements are marked on the map. The distribution of breaking points through the chromosomes of $\mathrm{D}$. mediopunctata is apparently non-random. Chromosomes X, II and IV show inversion polymorphisms. Chromosome II is the most polymorphic, with 17 inversions, 8 inversions in the distal region and 9 in the proximal region. Chromosome $X$ has four different gene arrangements, while chromosome IV has only two.

Key words: linkage disequilibrium - gene order - cytogenetic analysis - chromosome mapping

Drosophila mediopunctata is a Neotropical species with a wide geographical distribution, found in many parts of Brazil and in El Salvador (Val et al. 1981). In some areas, particularly in the South or at high altitudes during the winter, it may be the commonest of the Drosophila species collected (Saavedra et al. 1995). D. mediopunctata belongs to the tripunctata group (Frota-Pessoa 1954), which is the second largest group of the Neotropical region (Vilela 1992). Its identification is relatively easy, contrasting with most species of the group that are difficult to identify (Vilela 1992). Various aspects of its biology make $D$. mediopunctata an interesting model for studies of the genetics of natural populations (for a review and discussion, see Klaczko 1995).

D. mediopunctata has 5 pairs of acrocentric chromosomes and a pair of dots (Kastritsis 1966). Chromosomes $\mathrm{X}$, II and IV show inversion polymorphisms. Chromosome II is the most polymorphic with 17 inversions. Chromosome $\mathrm{X}$ has four different gene arrangements, one of them associated to the "sex-ratio" phenomenon. Chromosome IV has only two gene arrangements (Carvalho et al. 1989, Klaczko et al. 1990, Peixoto \& Klaczko 1991).

The presence of chromosome inversion polymorphisms is typical of various species of Drosophila (Krimbas \& Powell 1992, 2000). These polymorphisms are often under selection, being dynamic with seasonal, geographical and long-term frequency variations (Sperlish \& Pfriem 1986, Anderson et al. 1991). In D. mediopunctata

Supported by grants from Conselho Nacional de Desenvolvimento Científico e Tecnológico $(\mathrm{CNPq})$ and Coordenação de Aperfeiçoamento de Pessoal de Ensino Superior (Capes); Fundação de Amparo à Pesquisa de São Paulo (Fapesp); Fundo de Apoio ao Ensino e Pesquisa (Faep-Unicamp).

${ }^{+}$Corresponding author. Fax: +55-19-378.86535. E-mail: LBK@unicamp.br

Received 12 November 2001

Accepted 6 February 2002 we also found seasonal, micro- and macrogeographic variations in the frequencies of the karyotypes (Klaczko 1995). Moreover, there are differences among karyotypes for characters associated with fitness, such as size and shape (Bitner-Mathé et al. 1995).

Kastritsis (1966) made a map of the polytene chromosomes of D. mediopunctata using a single isofemale line. However, he was able to identify two inversions on chromosome II. We now present a more detailed map, locating the breaking points of all the inversions.

\section{MATERIALS AND METHODS}

Strains used and field collection - To analise the gene arrangements, we used $D$. mediopunctata isofemale lines maintained in our laboratory (Laboratório de Genética, Ecologia e Evolução de Drosofilídeos, Unicamp, Brazil). They were originally set up with flies collected in various places in Brazil (Atibaia, SP; Campinas, SP; Itatiaia, MG; Juiz de Fora, MG; Jundiaí, SP; Porto Alegre, RS). This ensured the sampling of the most common inversions. To obtain the missing arrangements, we made field trips to the Reserva Santa Genebra (Campinas, SP) and to the Japi Mountains (Jundiaí, SP). However, the mapping of some very rare inversions $(D L, P A 8, P C 5$ and $P C 3)$ was based only on the analysis of old chromosome preparations and of photographs from the laboratory collection.

In the field collections, we used fermented banana baits or traps, as described in Peixoto and Klaczko (1991) and Medeiros and Klaczko (1999). The analysis methodology followed the procedure described by Peixoto and Klaczko (1991).

Preparation of the polytene chromosomes - The polytene chromosomes were prepared using third instar larvae, following the method described by Ashburner (1989), with $1 \mathrm{~N} \mathrm{HCl}$ and lacto-acetic orcein.

Map drawing - Various drawings of D. mediopunctata polytene chromosomes were made using a camera lucida (1700x magnification). To prepare the consensus map, we used up to 10 drawings for each region from different nuclei. 


\section{RESULTS AND DISCUSSION}

Cytological map - The cytological map of the five acrocentric chromosomes of $D$. mediopunctata is shown in Fig. 1. We followed the convention of Bridges (1935) in D. melanogaster, dividing the polytene chromosomes of D. mediopunctata in a total of 100 regions, numbered from 1 to 100 . Each chromosome has 20 segments and a remarkable band at the beginning of each segment. The numerical regions were subdivided in smaller fragments named with letters.

In the map published by Kastritsis (1966) each chromosome was divided in 10-11 segments named with letters. Our map is more detailed, but we preserved, whenever possible, Kastritsis divisions. However, we adopted numbers for the description of inversions, since it is more convenient, except for the second chromosome (see below).

In the map presented, there are 372 bands in chromosome X; 422 in chromosome II; 446 in chromosome III; 440 in chromosome IV; and 431 in chromosome V; with a total of 2,111 bands.

In spite of the misleading simplicity, the exact determination of the number of bands in the cytological maps remains an unsolved problem. In species of Diptera, the numbers vary from 1,500 to 5,000 . It is unlikely that this is due to a fundamental genomic variation. Of course, there are objective and subjective factors that affect the determination of the number of bands. We now know that artifacts of fixation with acetic acid cause the appearance of double bands and consequently an overestimate of the number of bands. Moreover the identification of bands depends also on the physiological state of the cell, on the degree of polytenization and on the stretching of the chromosomes. Using electron microscopy in three species, (Chironomus tentans, D. melanogaster and D. hydei) the best estimates of the number of bands were obtained as being around 3,500. This number is considered typical for all Diptera. But, in chromosomes normally stretched, 2,500 bands can usually be identified (Zhimulev 1996). Thus, the number we obtained in our work $(2,111)$ corresponds to the normal stretching of the chromosomes.

Description of the gene arrangements - The most convenient way to describe a gene arrangement is by comparison to a standard. For chromosomes X, III, IV and V we chose the commonest configuration in natural populations as the standard. For the second chromosome there are too many arrangements and no single one can be considered the most representative of the species. We chose $D I-P C O$ as standard, since both $D I$ and $P C O$ are, respectively, the probable ancestrals for the distal and proximal regions (Peixoto \& Klaczko 1991). The breaking points for each of the inversions are shown in Fig. 1.

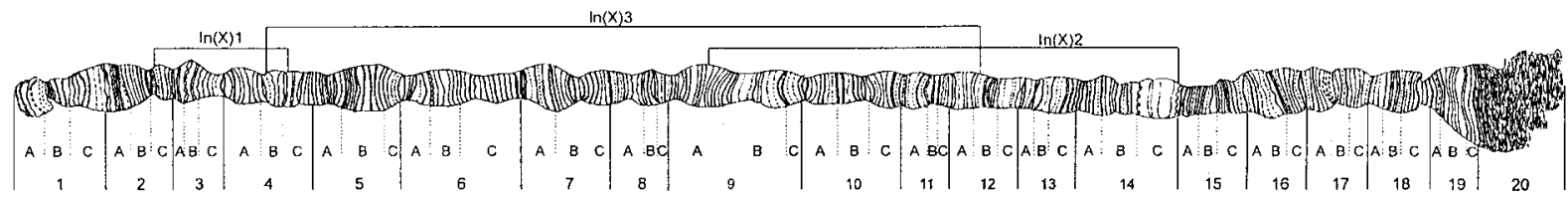

II

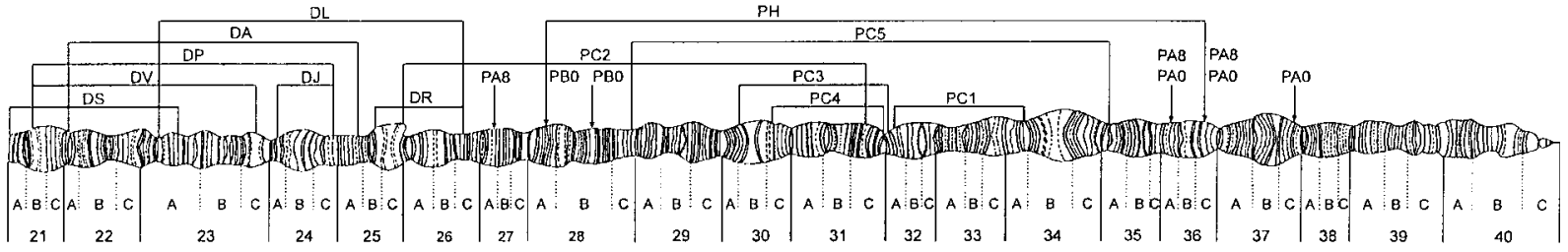

III

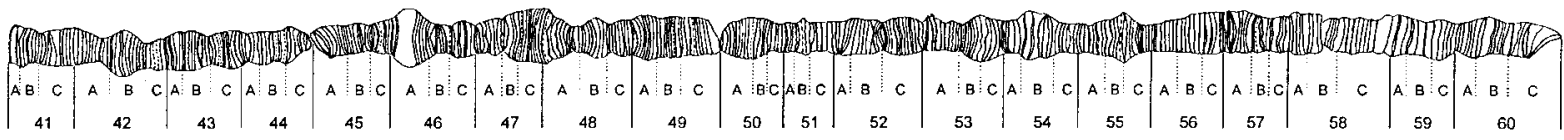

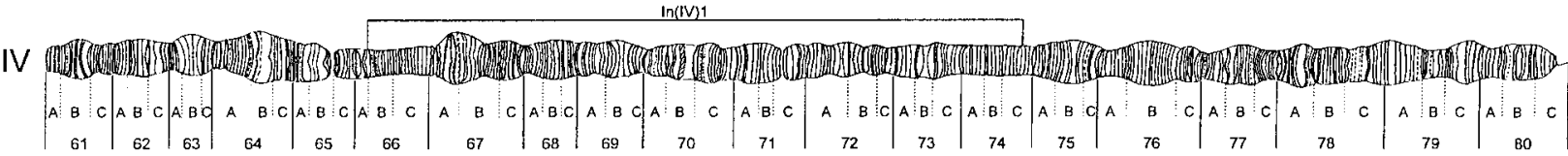

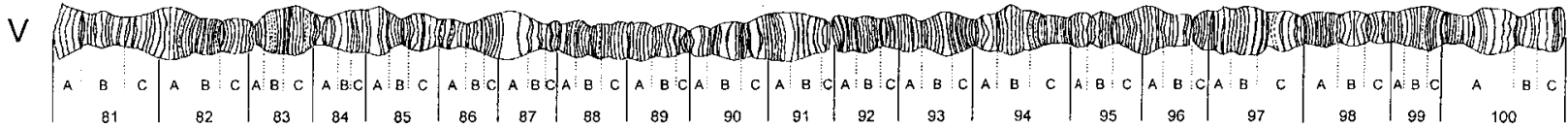

Fig. 1: polytene chromosome map of Drosophila mediopunctata with inversion breakpoints presented. Centromeres are shown to the right, telomeres to the left. 
Chromosome II is the most polymorphic for inversions. Its complexity can be simplified by assigning the inversions to two groups according to the chromosome region: distal and proximal. Figs $2 \mathrm{~A}, \mathrm{D}$ show, respectively, the double heterokaryotypes $D A-P A O / D I-P B O$ and $D S$ $P C O / D I-P B O$ which are characteristic of the configurations found in nature and where one can clearly see the two regions. The distal group includes 8 inversions: $D I$, $D S, D V, D P, D A, D L, D R$ and $D J$. In the proximal region, there are 9 inversions: $P C 0, P C 1, P C 2, P C 3, P C 4, P C 5$, $P B O, P A O$ and $P A 8$. Figs $2 \mathrm{~B}, \mathrm{C}, \mathrm{E}$ show, respectively the heterokaryotypes $D P / D I, D V / D I$, and $P A O / P C O$.

In almost all combinations between proximal and distal inversions there is no overlap between the two regions. Thus, in principle recombination between them can occur. However, there is a very strong linkage disequilibrium and consequently, the number of configurations found in nature is reduced (Peixoto \& Klaczko 1991).

The distal inversions and their relation to $D I$ are shown diagrammatically in Fig. 1. Inversion $D J$ is presented as a separated arrangement, but it is nearly always found associated to $D V$ which is also a distal inversion. This latter can be found isolated with good frequency. The combination $D V+D J$ was previously called $D T$ (Peixoto \& Klaczko 1991).

The proximal inversions can be divided in three phylads (Dobzhansky 1970): $P C, P B$ and $P A$. The phylad
$P C$ (Fig. 1) is made up of six gene arrangements: $P C O$, $P C 1, P C 2, P C 3, P C 4$ and $P C 5$. These latter five can be considered derived from $P C O$.

The $P A$ phylad has two gene arrangements: $P A O$ and $P A 8$ (Fig. 1). PAO is complex, since it is an intrachromosomal transposition of two inverted fragments: $\operatorname{In}(2) P A O[=\operatorname{In}(2)$ $28 \mathrm{~A} ; 36 \mathrm{~A} ; 36 \mathrm{C} ; 37 \mathrm{C}]$. The heterokaryotypes $P C O / P A O$ and $P B O / P A O$ display complicated configurations (with segments 36A-36C always unpaired).

$P B O$ is isolated in the $P B$ phylad (Fig. 1). Compared to $P C O$, it is an inverted insertional transposition in the second chromosome: $\operatorname{In}(2) P B O[=\operatorname{In}(2) 28 \mathrm{~A} ; 28 \mathrm{~B} ; 36 \mathrm{C}]$.

The arrangements $P A O, P B O$ and $P C O$ are overlapping inversions. This allows us to make inferences about their phylogenetic relations (Dobzhansky \& Sturtevant 1938). If compared, one can not relate any two of these inversions through a single inversion event. However, it is possible to assume and draw a hypothetical arrangement $(\mathrm{PH})$ that is a parsimonious explanation relating the three gene inversions (Fig. 3) as it was done with the chromosomes of D. pseudoobscura (Dobzhansky 1970).

Chromosome $\mathrm{X}$ has four gene arrangements: Standard, 1,2 and 3 (Fig. 1). There is a strong linkage disequilibrium between $\operatorname{In}(X) 1$ and $\operatorname{In}(X) 2$. They are often found together (Peixoto \& Klaczko 1991).

In chromosome IV, aside from the Standard gene arrangement, we found only one inversion, $\operatorname{In}(I V) 1$ (Fig. 1).

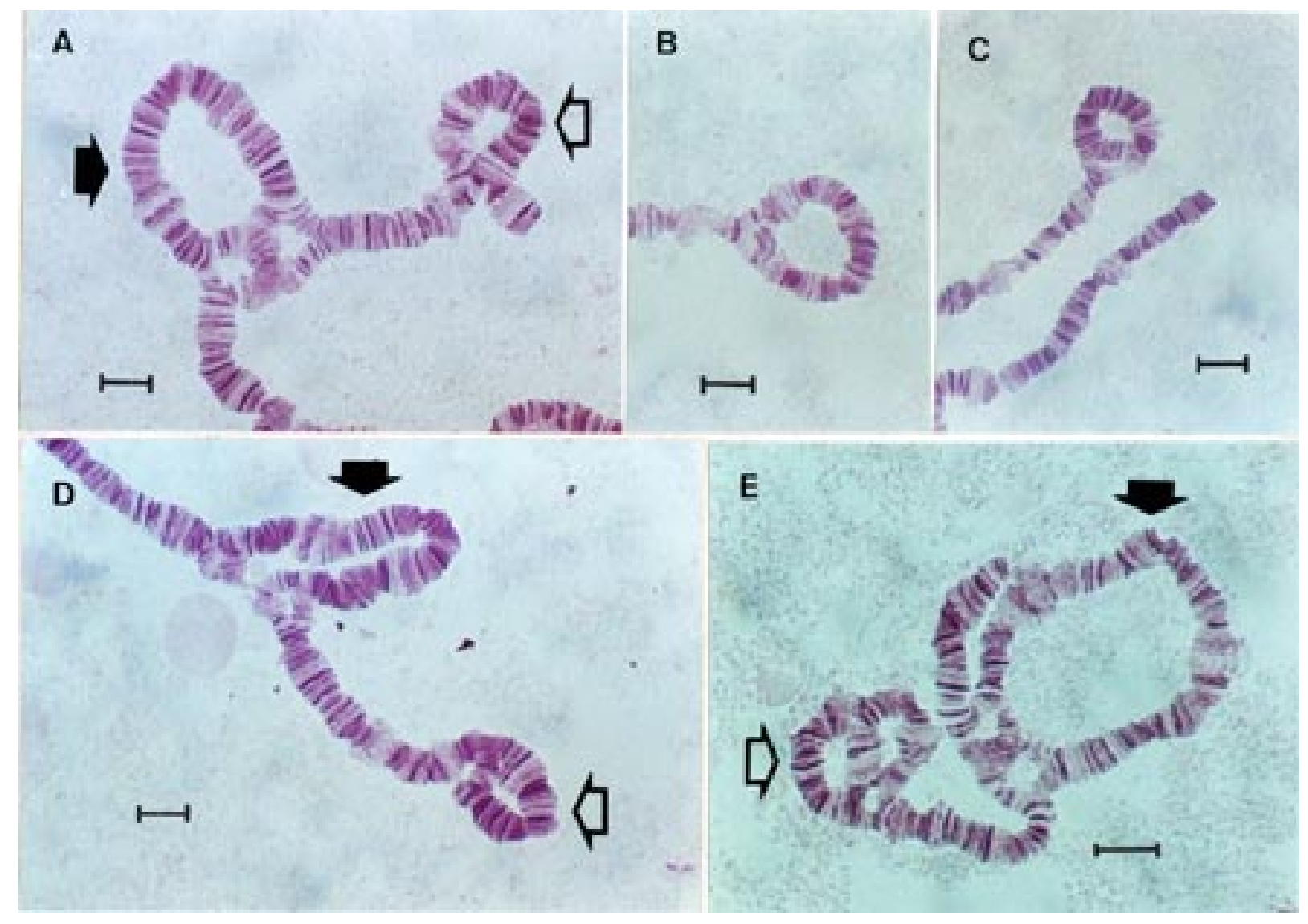

Fig. 2: the most frequent inversions of Drosophila mediopunctata. A: DA-PAO/DI-PBO; B: DP/DI; C: DV/DI; D: DS-PCO/DI-PBO; E: $D A-P A O / D S-P C O$. The open arrows point to the distal region and the closed arrows to the proximal region. Bar $=100 \mu \mathrm{m}$ 


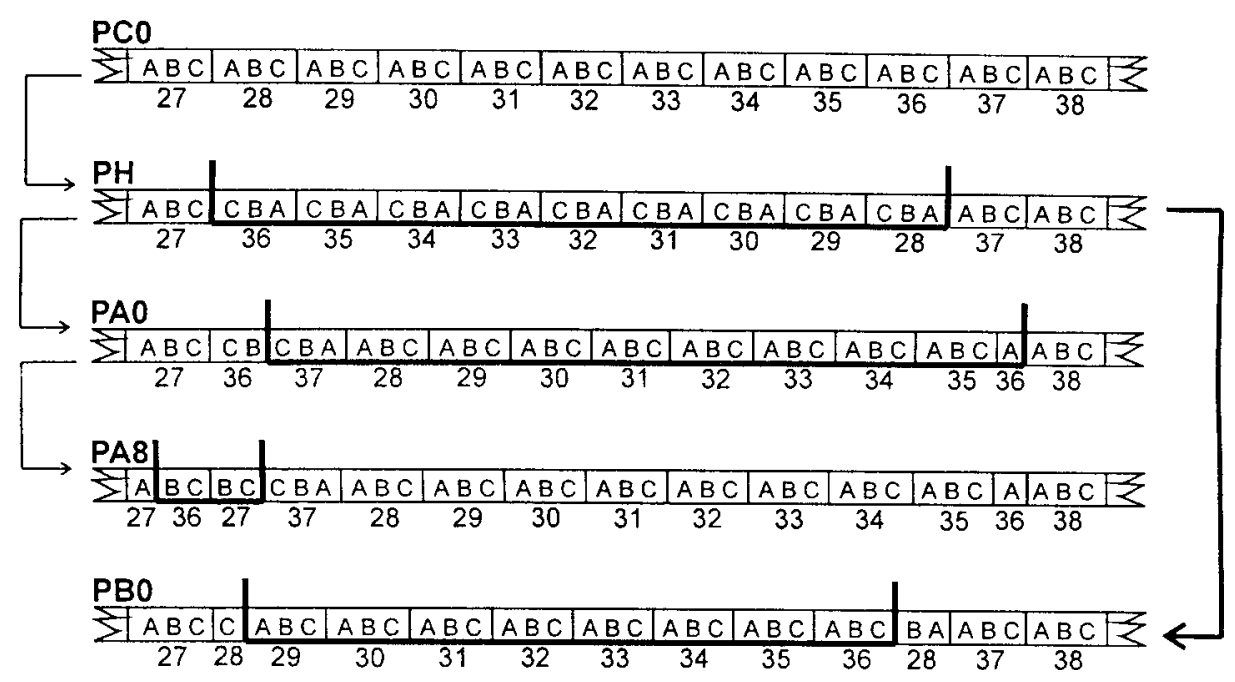

Fig. 3: diagram of the proximal inversions showing the sections and subdivisions of the standard map. PC0 is considered to be the ancestral. $\mathrm{PH}$ is a hypothetical rearrangement that is a parsimonious explanation to relate PA0, PB0 and PC0. PA8 is probably derived from PA0.

The distribution of breaking points through the chromosomes of $D$. mediopunctata is apparently non-random. The second chromosome is the most saturated. In this chromosome, we found a subterminal inversion [In(2)DS, Fig. 1], but no subbasal inversions. The majority of the breaking points are found in its distal half portion. In some cases, different inversions share cytologically the same breaking point (Fig. 1).

\section{ACKNOWLEDGEMENTS}

To Hermes F Medeiros and Horácio Montenegro for the decisive help in field collections, to Maria Aparecida Ramos Libânio for technical help, and to Edward Hogan for correcting the English version.

\section{REFERENCES}

Anderson WW, Arnold J, Baldwin DG, Beckenbach AT, Brown CJ, Bryant SH, Coyne JA, Harshman LG, Heed WB, Jeffery DE, Klaczko LB, Moore BC, Portert JM, Powell JR, Prout T, Schaeffer SW, Stephens JC, Taylor CE, Turner ME, Williams GO, Moore JA 1991. Four decades of inversion polymorphism in Drosophila pseudoobscura. Proc Natl Acad Sci USA 88: 10367-10371.

Ashburner M 1989. Drosophila: A Laboratory Manual, CSHL Press, Cold Spring Harbor, New York, p. 31.

Bitner-Mathé BC, Peixoto AA, Klaczko LB 1995. Morphological variation in a natural population of Drosophila mediopunctata: altitudinal cline, temporal changes and influence of chromosome inversions. Heredity 75: 54-61.

Bridges CB 1935. Salivary chromosome maps with a key to the banding of the chromosomes of Drosophila melanogaster. $J$ Hered 26: 60-64.

Carvalho AB, Peixoto AA, Klaczko LB 1989. Sex-ratio in Drosophila mediopunctata. Heredity 62: 425-428.

Dobzhansky Th, Sturtevant AH 1938. Inversions in the chromosomes of Drosophila pseudoobscura. Genetics 23: 2864.

Dobzhansky Th 1970. Genetics of the Evolutionary Process, Columbia University Press, New York, 505 pp.

Frota-Pessoa O 1954. Revision of the Tripunctata Group of Drosophila with Description of Fifteen New Species (Drosophilidae, Diptera), João Haupt \& Cia. Ltda.,
Curitiba, p. 254-304.

Kastritsis CD 1966. Cytological Studies of Some Species of the tripunctata Group of Drosophila, Univ Texas Publs, Texas, p. 413-474.

Klaczko LB 1995. Population genetics of Drosophila mediopunctata. In L Levine, Genetics of Natural Populations. The Continuing Importance of Theodosius Dobzhansky, Columbia University Press, New York, p. 140153.

Klaczko LB, Otto PA, Peixoto AA 1990. Allele frequency estimates when only heterozygotes can be recognized: method of estimation and application in the case of chromosomal inversion polymorphisms in Drosophila. Heredity 64: 263270.

Krimbas CB, Powell JR 1992. Drosophila Inversion Polymorphism, CRC Press, Boca Raton, FL, 560 pp.

Krimbas CB, Powell JR 2000. Inversion polymorphisms in Drosophila. In RS Singh, CB Krimbas (eds), Evolutionary Genetics: from Molecules to Morphology, Vol. 1, Cambridge University Press, Cambridge, p. 284-299.

Medeiros HF, Klaczko LB 1999. A weakly biased Drosophila trap. DIS 82: 100-102.

Peixoto AA, Klaczko LB 1991. Linkage disequilibrium analysis of chromosomal inversion polymorphisms of Drosophila. Genetics 129: 773-777.

Saavedra CC, Callegari-Jacques SM, Napp M, Valente VLS 1995. A descriptive and analytical study of neotropical drosophilid communities. J Zool Syst Evol Research 33: 6274.

Sperlish D, Pfriem P 1986. Chromosomal polymorphism in natural and experimental populations. In M Ashburner, HL Carson, JN Thompson Jr (eds), The Genetics and Biology of Drosophila, Vol. 3e, Academic Press, New York, p. 257309.

Val FC, Vilela CR, Marques MD 1981. Drosophilidae of the Neotropical Region. In M Ashburner, HL Carson, JN Thompson Jr (eds), The Genetics and Biology of Drosophila, vol. 3a, Academic Press, New Yorkp, p. 123-168.

Vilela CR 1992. On the Drosophila tripunctata species group (Diptera, Drosophilidae). Rev Bras Ent 36: 197-221.

Zhimulev IF 1996. Morphology and structure of polytene chromosomes. Adv Genet 34: 1-497. 